\title{
Effect of Carnauba Wax and Coconut Fiber Contents on Tensile Properties of Corn Starch-Based Biocomposites
}

\author{
Áleft Verlanger Rocha Gomes ${ }^{a} *^{-}$, Francielle Cristine Pereira Gonçalves ${ }^{b}$, Manoel Quirino \\ da Silva Júnior ${ }^{a}$, Ricardo Henrique de Lima Leite ${ }^{b}$,Francisco Klebson Gomes dos Santos ${ }^{c}$ ๑, \\ Edna Maria Mendes Aroucha ${ }^{d}$
}
${ }^{a}$ Centro de Ciências Exatas e Naturais, Universidade Federal Rural do Semi-Arido, Mossoro, RN, Brasil
${ }^{b}$ Departamento de Engenharia e Tecnologia, Universidade Federal Rural do Semi-Árido, Mossoro, RN, Brasil
'Departamento de Ciências Naturais, Matemática e Estatística, Universidade Federal Rural do Semi-Árido, Mossoro, RN, Brasil
${ }^{d}$ Departamento de Engenharia e Ciências Ambientais, Universidade Federal Rural do Semi-Árido, Mossoro, RN, Brasil

Received: January 20, 2019; Revised: May 21, 2019; Accepted: July 02, 2019

\begin{abstract}
This work aims investigate the changes on tensile properties of biocomposites obtained by addition of carnauba wax and coconut fibers in a corn starch matrix. The influence of carnauba wax and coconut fibers contents on tensile strength, modulus of elasticity and elongation at break was studied using a response surface methodology. A central composite design based on three levels of carnauba wax content $(0,10$ and $20 \%)$ and coconut fibers content $(0,10$ and $20 \%)$ was elaborated. Empirical models were obtained to describe these properties as function of coconut fiber and carnauba wax contents. Optical microscopy was carried out to visualize the dispersion and interactions between coconut fibers, carnauba wax and starch matrix in the biocomposites. In presence of carnauba wax, the biocomposite became more compact and with a better interaction between the corn starch-based matrix and coconut fibers reinforcement. It was observed that tensile strength and modulus of elasticity rise with the increase in carnauba wax and coconut fiber contents. Moreover, the elongation at break increases with the addition of coconut fiber, while a decrease in the values of this property occurs with the addition of carnauba wax.
\end{abstract}

Keywords: surface response methodology, central composite design, tensile strength, modulus of elasticity, elongation.

\section{Introduction}

The development and use of biodegradable and renewable materials have attracted the attention of society in view of the problems caused by increased solid waste production, pollution and greenhouse gases, as well as, the shortage of non-renewable raw materials. Synthetic polymers are materials widely used in disposable objects and cause a serious problem due its biological recalcitrance since these materials need hundreds of years to degrade in environment. Also, most synthetic polymers are currently obtained from non-renewable sources like petroleum. Therefore, ecological friendly materials able to substitute artificial polymers are being investigated by researchers around the world ${ }^{1,2}$.

An alternative to conventional polymer objects is using biodegradable objects made from biopolymers, like starch. Starch-based materials stand out as promising candidates to replace polymers from petroleum due its biodegradability, low cost, and to be obtained from a renewable resource. However, these materials have low flexibility, high brittleness and hydrophilicity ${ }^{1,3}$. In order to improve the flexibility of these materials, plasticizers such as glycerol and others polyols can be added to starch matrix. On the other hand, natural fibers have also been used to reinforce starch matrices, resulting more strength materials ${ }^{4,5,6}$.

The materials resulting from the combination of a biopolymer matrix, like starch, reinforced with vegetable fibers are known as biocomposites. These can be disposed of without injury to the environment and arise as an alternative to synthetic polymer matrix composites ${ }^{7,8}$. Nevertheless, the high moisture absorption ability of the biocomposites produced from starch, because its high hydrophilic character, compromises its mechanical properties and life cycle ${ }^{9}$. A solution to increase the hydrophobicity of these materials and improving their water barrier properties is add lipids, 
such as carnauba wax, to biocomposites matrices. Although adding lipids can improve water barrier properties of starch matrix, mechanical properties of biocomposites are likewise affected ${ }^{10,11}$. Thereby, it is necessary to investigate how the lipids content modify the mechanical properties of biocomposites. Moreover, fibers present in biocomposites can interact with the particles of lipids changing mechanical behavior of these materials.

This work aims investigate the effect of fiber and wax contents in tensile properties of biocomposites constituted by a corn starch-based matrix, reinforced with coconut fibers and added of carnauba wax. A central composite experimental design was carried out with three levels for each factor (fiber and wax contents). A variance analysis (ANOVA) permitted select the significant effects of factors and interactions. Then, empirical polynomial models were fitted to experimental results and a response surface methodology was employed to describe changes in tensile strength, modulus of elasticity and elongation at break of the biocomposites, as function of coconut fiber and carnauba wax contents. Finally, optical microscopy aided to elucidate the morphology of biocomposites and the interactions between matrix, fibers and wax particles at microscopic level.

\section{Experimental}

\subsection{Materials}

Carnauba wax type I (Agrocera, Russas-CE, Brazil) and coconut fibers (Fazenda Morada Nova, Mossoró-RN, Brazil) were kindly given away by manufacturers. The corn starch (3 Corações Alimentos S.A., Mossoró-RN, Brazil) and glycerol 99.5 \% (Dinâmica Química Contemporânea, São Paulo, Brazil) were purchased from commerce and used without further purification. Osmosed water was used to prepare the precursor mixtures for biocomposites.

\subsection{Methods}

\subsubsection{Experimental design and statistical analysis}

A Central Composite Design (CCD) with two independent variables ( $n=2$, number of factors) was used to studied the effects of coconut fiber (CF) and carnauba wax (CW) contents on tensile properties of corn starch-based biocomposites. A total of 13 experiments were run, being sufficient to calculate the coefficients of a second-order polynomial regression model for two variables. The number of runs corresponding at four $\left(2^{n}\right)$ factorial points added of four $(2 n)$ axial points and five replicates at central point. Each factor was investigated at three levels: $-1,0$ and +1 , in coded values; corresponding at 0,10 and $20 \%$, in real values. The dependent variables (responses) evaluated were tensile strength (TS), modulus of elasticity (ME) and elongation at rupture (El). The behavior of each response was explained by an empirical polynomial model as showed in Equation 1.

$Y_{i}=b_{0}+b_{1} X_{1}+b_{2} X_{2}+b_{11} X_{1}^{2}+b_{22} X_{2}^{2}+b_{12} X_{1} X_{2} \quad(i=1,2$ or 3$)$

Here, $\mathrm{Y}_{\mathrm{i}}$ represents dependent variables, where $\mathrm{Y}_{1}$ was tensile strength in $\mathrm{MPa}, \mathrm{Y}_{2}$ modulus of elasticity in $\mathrm{MPa}$, and $\mathrm{Y}_{3}$ was elongation at rupture in percentage; $\mathrm{X}_{1}$ and $\mathrm{X}_{2}$ were the independent variables, coconut fibers and carnauba wax contents, respectively, expressed in percentage; $b_{0}$ was intercept, $b_{1}$ and $b_{2}$ linear coefficients, $b_{11}$ and $b_{22}$ quadratic coefficients and $b_{12}$ the interactive coefficient.

A variance analysis (ANOVA) and $F$ test were performed to verify if the models were statistically significant at $\mathrm{p}<$ 0.05 . For the models in which the $F_{\text {calculated }}$ was superior to the $F_{\text {tabulated }}$ and $R^{2} \geq 0.75$, the response surfaces were represented as three-dimensional contour plots. During the adjustment of the models, non-significant effects were ignored. All Statistical analysis of data obtained through the experimental design was performed, using the software Statistica ${ }^{\circledR}$ version 13.5 (TIBCO softtware Inc., USA).

\subsubsection{Preparation of biocomposites}

The biocomposites were manufactured by casting methodology. Precursor blends were prepared with a mass of dry matter total fixed at $20 \%$ (w/w) using osmosed water as solvent. Dry matter mass was considered as the sum of masses for the corn starch, coconut fibers and carnauba wax. The masses of coconut fibers and carnauba wax varied in accord with contents stablished in the experimental design for each essay, as described at Table 1. The mass of corn starch was determined by difference between the mass of dry matter total and the masses of fibers and wax used in each run. The mass of plasticizer (glycerol) was calculated in order to maintain its content fixed at $15 \%(\mathrm{w} / \mathrm{w})$ of the biopolymer mass. Previous the preparation, coconut fibers were cut and its lengths uniformized at $6.55 \pm 0.71 \mathrm{~mm}$. The first step in process of blend preparation was the dispersion in water of corn starch, glycerol and coconut fibers, according the calculated amounts for each run. This mixture was heated and the temperature kept constant at approximately $90{ }^{\circ} \mathrm{C}$, under constant mechanical stirring until complete starch gelatinization. A change in mixture aspect from opaque to translucid indicates the complete starch gelatinization, which occurs in about 25 minutes of heating. The carnauba wax was added after starch gelatinization and enough stirring to ensure mixture homogeneity. The temperature and stirring conditions required in experiments were got by a mechanical homogenizer (TE-099, Tecnal) and a thermostatic bath. Once prepared, $1000 \mathrm{~g}$ of each precursor mixture were deposed in trays $(20 \mathrm{~cm} \times 30 \mathrm{~cm})$ and dried in oven with air recirculation (TE-394/1, Tecnal) at $60^{\circ} \mathrm{C}$ during 48 hours. 
Table 1. Central composite design matrix with real and coded (in parentheses) values for independent variables, with $\mathrm{X}_{1}=$ coconut fiber content (CF) and $\mathrm{X}_{2}=$ carnauba wax content (CW); and means for response variables, with $\mathrm{Y}_{1}=$ tensile strength (TS), $\mathrm{Y}_{2}=$ modulus of elasticity $(\mathrm{ME})$ and $\mathrm{Y}_{3}=$ elongation at break $(\mathrm{El})$.

\begin{tabular}{cccccc}
\hline Run & $\mathbf{X}_{\mathbf{1}}(\mathbf{C F}) \mathbf{\%}$ & $\mathbf{X}_{\mathbf{2}}(\mathbf{C W}) \mathbf{\%}$ & $\mathbf{Y}_{\mathbf{1}}(\mathbf{T S}) \mathbf{M P a}$ & $\mathbf{Y}_{\mathbf{2}}(\mathbf{M E}) \mathbf{M P a}$ & $\mathbf{Y}_{\mathbf{3}}(\mathbf{E I}) \mathbf{\%}$ \\
\hline 1 & $0(-1)$ & $0(-1)$ & 2.57 & 77.1 & 1.32 \\
2 & $10(0)$ & $0(-1)$ & 1.65 & 48.6 & 4.03 \\
3 & $20(+1)$ & $0(-1)$ & 1.99 & 53.5 & 5.28 \\
4 & $0(-1)$ & $10(0)$ & 1.64 & 80.0 & 1.60 \\
5 & $20(+1)$ & $10(0)$ & 3.08 & 77.3 & 5.50 \\
6 & $0(-1)$ & $20(+1)$ & 0.63 & 55.6 & 1.25 \\
7 & $10(0)$ & $20(+1)$ & 2.67 & 94.2 & 2.95 \\
8 & $20(+1)$ & $20(+1)$ & 3.46 & 125.2 & 3.18 \\
10 & $10(0)$ & $10(0)$ & 2.23 & 123.5 & 2.08 \\
11 & $10(0)$ & $10(0)$ & 2.51 & 128.0 & 2.09 \\
12 & $10(0)$ & $10(0)$ & 2.69 & 116.1 & 2.30 \\
\end{tabular}

\subsubsection{Preparation and conditioning of test specimens}

After manufacture of biocomposites, test specimens were cut with dimensions of $100 \mathrm{~mm} \times 20 \mathrm{~mm}$. Then, test specimens were conditioned in a hermetically sealed vessel at a constant relative humidity of $49 \%$. The humidity was maintained constant using a saturated saline solution of potassium carbonate $\left(\mathrm{K}_{2} \mathrm{CO}_{3}\right)$, prepared according to ASTM E104 ${ }^{12}$. The mass of test specimens was measured periodically until equilibrium conditions be attained and verified by have no changes in their masses over time. The Figure 1 shows test specimens of biocomposites prepared according to coconut fibers and carnauba wax contents specified by experimental design stated in Table 1.

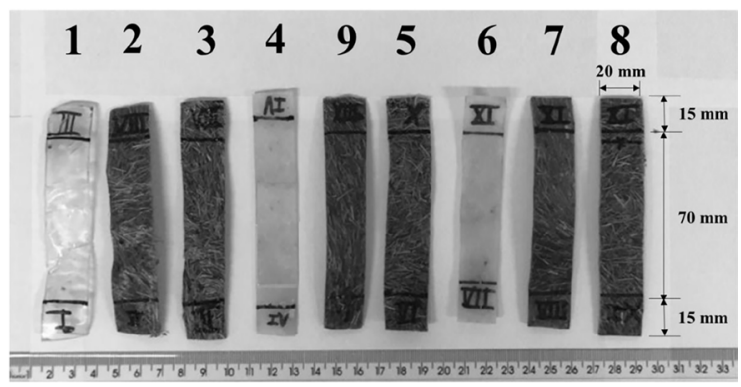

Figure 1. Test specimens of biocomposites for the different essays of the experimental design (digits at the top correspond to essay number in Table 1)

\subsubsection{Measurement of thickness}

The thickness of test specimens was measured at five random points with an EDA analogical micrometer with $0.01 \mathrm{~mm}$ resolution. The averages of these values were used to determine the mechanical properties of each specimen.

\subsubsection{Optical Microscopy}

Optical microscopy was carried out to visualize the dispersion and interactions between coconut fibers, carnauba wax and starch matrix in the biocomposites. The equipment used was the Nikon SMZ18 Stereo Microscope assisted by the NIS Elements D software for viewing, capturing and storing images.

\subsubsection{Mechanical Testing}

The characterization of the biocomposites was carried out by means of a tensile test according to ASTM D3039 ${ }^{13}$. The equipment used to perform the test was the Universal Testing Machine, model DL10000 of EMIC, with capacity $100 \mathrm{kN}$, load cell of $5 \mathrm{kN}$ and software TESC for data acquisition. The test was performed at a temperature of $23^{\circ}$ $\mathrm{C}$ and relative humidity of $49 \%$. Five specimens were tested for each run of the experimental design.

\section{Results and Discussion}

\subsection{Optical microscopy}

Figure 2 shows the morphology and interfacial adhesion of some biocomposites prepared with corn starch matrix reinforced with coconut fiber and with carnauba wax as additive.

The biopolymeric matrix of corn starch is shown in Figure 2 (a), where it is possible to observe the cross-sectional area of the sample that has a homogeneous and smooth morphology, possibly indicating a fragile fracture. This is because the matrix contains a low glycerol (plasticizer) content, what provides greater intermolecular interaction and, consequently, a lower mobility of the macromolecules, 


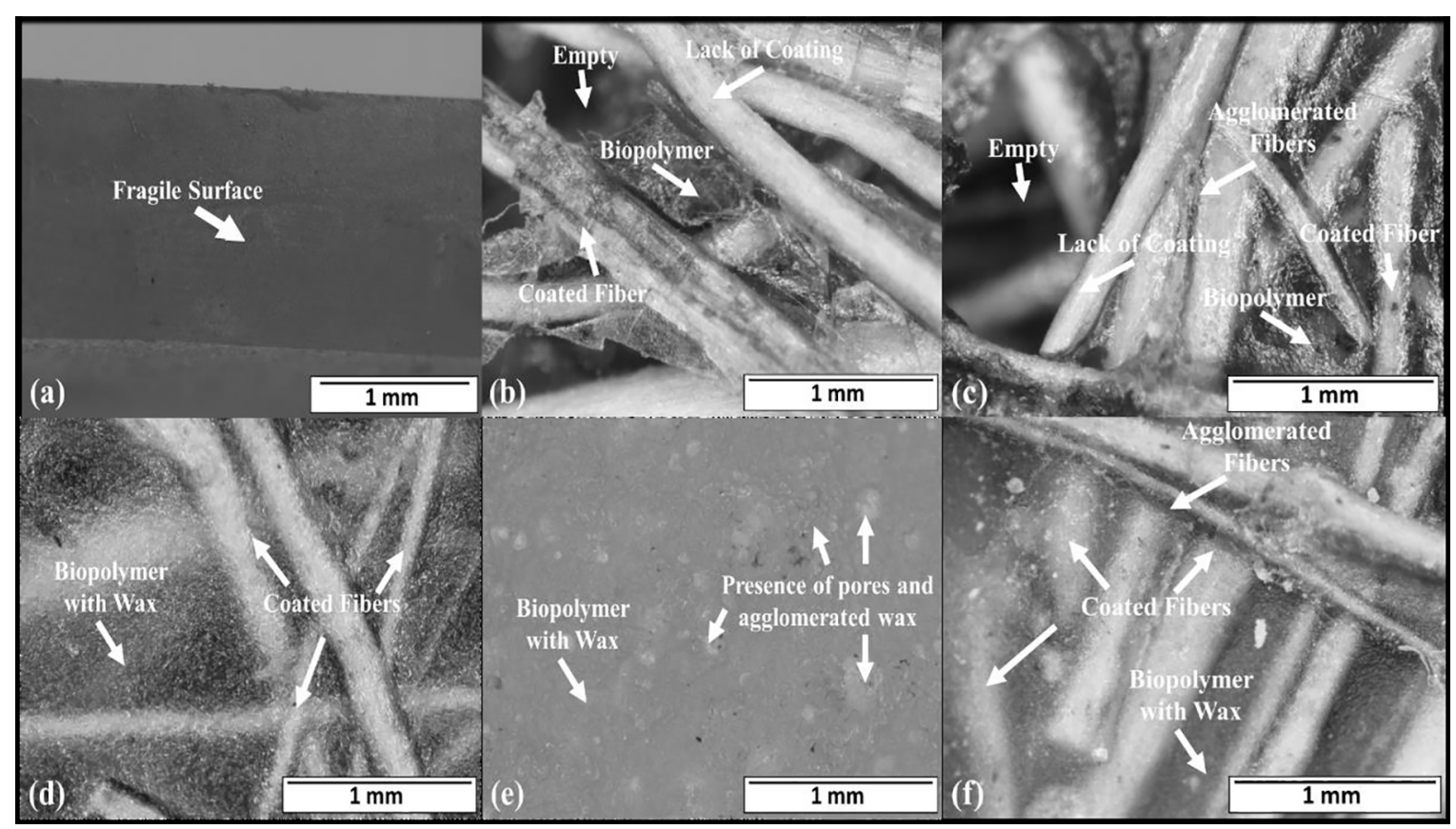

Figure 2. Optical microscopy of (a) Matrix of corn starch; (b) Biocomposite with $10 \%$ coconut fiber and (c) $20 \%$ coconut fiber; (d) Biocomposite with $10 \%$ coconut fiber and $10 \%$ carnauba wax; (e) Biocomposite with $20 \%$ carnauba wax; (f) Biocomposite with $20 \%$ coconut fiber and $20 \%$ carnauba wax.

resulting in a more fragile structure, as also observed by Ramírez et al. ${ }^{9}$ and Jouki et al. ${ }^{14}$.

In Figure 2(b) it is possible to verify the corn starchbased biocomposite reinforced with coconut fiber without carnauba wax additive, where there is the presence of defects (voids) promoted by the poor dispersion of the coconut fibers in starch matrix. In addition, it is observed the absence of matrix coating around the fiber, characteristic of a poor interfacial adhesion between the fiber and matrix.

Figure 2(c) shows the morphology for a biocomposite which have a higher concentration of coconut fiber in relation to material showed in Figure 2(b). There are frequent defects in the biocomposite, possibly due to higher volume of fiber used, promoting a high agglomeration of the coconut fibers, and the lack of coating of the fibers by the matrix. These defects, also observed by Edhirej et al. ${ }^{15}$ at high concentrations of reinforcement, contribute to the presence of stress concentrators that can affect the mechanical properties of the biocomposites.

For the material shown in Figure 2(d) can be observed a random and homogeneous arrangement of the coconut fibers in corn starch matrix, without voids, as was also observed by Ramírez et al. ${ }^{9}$. In this case, the matrix is compact and dense, possibly due to the presence of the carnauba wax, which causes a decrease in the viscosity and hydrophilicity of the matrix, thus allowing a better dispersion of the coconut fibers during the production process of the biocomposite. It is observed a uniform coating of the fibers by the matrix, which promotes a better interfacial adhesion resulting in a good transfer of tension from the matrix to the fiber, as also observed by Lopez et al. ${ }^{16}$.

Figure 2(e) shows a corn starch matrix with high content of carnauba wax where is possible to observe a heterogeneous and porous surface. This can be attributed to the high amount of carnauba wax added and the inability to properly mix the hydrophobic wax with a starch hydrophilic matrix under such conditions. Thus, high wax contents provoke the formation of hydrophobic agglomerates in the matrix, as was also observed by Mehyar et al. ${ }^{17}$. This results in structural defects in the matrix that influence the mechanical strength and flexibility of the biocomposites, due to the formation of tension concentrators in the material.

Figure 2(f) shows the investigated biocomposite with the highest concentration of coconut fiber and carnauba wax. Herein is seen a well compacted and dense matrix, in which a good part of the fibers is well coated. This should provide an improvement in the mechanical resistance of materials. However, the high percentage of coconut fibers causes them to agglomerate in the matrix due to insufficient amount of polymer disponible to disperse the fibers, as was also observed by Ibrahim et al. ${ }^{18}$.

\subsection{Response Surfaces}

The experimental design with real and coded values for the independent variables, as well the means for the dependent variables investigated can be observed in Table 1. 
The regression coefficients, as well as the $\mathrm{R}^{2}, \mathrm{R}_{\text {adjusted }}$, $\mathrm{F}_{\text {calculated }}$ and $\mathrm{F}_{\text {tabulated }}$ for the models can be observed in Table 2. The omitted coefficients were no significant being ignored during model adjustment.

ANOVA was performed $(p<0.05)$ for the responses shown in Table 2 after an adjustment by disregarding some regression coefficients, in order to obtain the subset with highest $\mathrm{R}_{\text {adjusted }}$. In all cases the $\mathrm{R}^{2}$ was higher than 0.75 and the $\mathrm{F}_{\text {calculated }}>\mathrm{F}_{\text {tabulated }}$ for a confidence level of $95 \%$, indicating that the models were significant. Only statistically significant terms were considered in final models, as indicated.

The empirical models proposed to describe the tensile strength (TS), the modulus of elasticity (ME) and elongation at rupture $(\mathrm{El})$ of the studied biocomposites are described by Equations 2, 3 and 4, respectively.

$$
T S=2.1416-0.003 C W^{2}+0.008 C F \times C W
$$

$$
M E=64.671-0.254 C F^{2}+6.408 C W-0.341 C W^{2}
$$

$$
E l=1.090+0.216 C F-0.005 C F \times C W
$$

The response surfaces exhibited in Figure 3 were plotted to demonstrate how coconut fiber and carnauba wax contents affect the (a) tensile strength (TS), (b) modulus of elasticity $(\mathrm{ME})$ and (c) elongation at break (El) of investigated biocomposites.

It can be seen in Figures 3(a) and 3(b) that both carnauba wax and coconut fiber contents influence the tensile strength and modulus of elasticity of the materials, according to indicate by the models (Equations 1 and 2). In these models, a negative quadratic coefficient for the carnauba wax content is observed, which indicates a reduction in the tensile strength with the increase in this factor, as can be visualized in Figure 3(a). This occurs because the carnauba wax has a hydrophobic and antiplasticizing character, resulting in a porous matrix and formation of wax agglomerates, as seen previously in the optical microscopy. These defects cause a decrease in TS, as observed by Mehyar et al. ${ }^{17}$; Chiumarelli and Hubinger ${ }^{10,19}$.

The positive interactive coefficient for coconut fiber and carnauba wax contents observed in Equation 01 indicates a synergic effect between these factors in the increase of tensile strength. As can be observed in the micrographs - Figures 1(d) and 1(f), there was a greater compaction of the biocomposites with the concomitant presence of the fiber and the wax, which caused a better coating of the fibers by the matrix. This possibly results in a better interfacial adhesion, which provides a better transfer of tension, considering that there will be a greater interaction between the coconut fibers and the corn starch matrix, which have free hydroxyl groups and can interact by formation of hydrogen bonds. This increase in the tensile strength due to the presence of lignocellulosic fibers was also observed by several authors ${ }^{9,18,20}$.

For modulus of elasticity, it was observed that the empirical model presents a positive linear parameter for carnauba wax content, indicating that an increase in this factor causes an increase in that property, as can be seen in Figure 3(b). This is possibly due to increased stiffness of the biocomposites due to the presence, in carnauba wax, of hydroxylated, unsaturated esters from long chain fatty acids, as observed by Mehyar et al. ${ }^{17}$; Chiumarelli and Hubinger ${ }^{19}$.

It can be verified through Figure 3(c) that an increase in coconut fiber content rises the elongation at break for the investigated materials. This fact is also evidenced by the positive linear coefficient for the coconut fiber content effect in this response variable, according to the model represented by Equation 03 . This is because the biocomposite contains a low percentage of glycerol, resulting in a fragile matrix

Table 2. Regression, determination coefficients and $\mathrm{F}$ test for models, as described in Equation 1, for response variables, with $\mathrm{Y}_{1}=$ tensile strength (TS), $\mathrm{Y}_{2}=$ modulus of elasticity (ME) and $\mathrm{Y}_{3}=$ elongation at break (El).

\begin{tabular}{ccccc}
\hline \multirow{2}{*}{ Type of coefficients } & $\begin{array}{c}\text { Coefficient codes } \\
\text { (factors) }\end{array}$ & $\mathbf{Y}_{1}(\mathbf{T S}) \mathbf{M P a}$ & $\mathbf{Y}_{2}$ (ME) MPa & $\mathbf{Y}_{3}$ (EI) \% \\
\cline { 3 - 5 } Intercept & $\mathrm{b}_{0}$ & $2.146^{*}$ & $64.671^{*}$ & $1.090^{*}$ \\
Linear coefficients & $\mathrm{b}_{1}\left(\mathrm{X}_{1}\right)$ & -0.019 & 3.743 & $0.216^{*}$ \\
& $\mathrm{~b}_{2}\left(\mathrm{X}_{2}\right)$ & - & $6.408^{*}$ & - \\
Quadratic coefficients & $\mathrm{b}_{11}\left(\mathrm{X}_{1} \cdot \mathrm{X}_{1}\right)$ & - & $-0.254^{*}$ & - \\
Interactive coefficient & $\left.\mathrm{b}_{22} \mathrm{X}_{2} \cdot \mathrm{X}_{2}\right)$ & $-0.341^{*}$ & $-0.005^{*}$ \\
\hline \multirow{2}{*}{ Determination coefficients } & $\mathrm{b}_{12}\left(\mathrm{X}_{1} \cdot \mathrm{X}_{2}\right)$ & $0.003^{*}$ & 0.138 & 0.775 \\
\hline \multirow{2}{*}{ F-values } & $\mathrm{R}^{2}$ & 0.851 & 0.814 & 0.730 \\
\hline
\end{tabular}

*Statistically significant values for $\mathrm{p}<0.05$. 

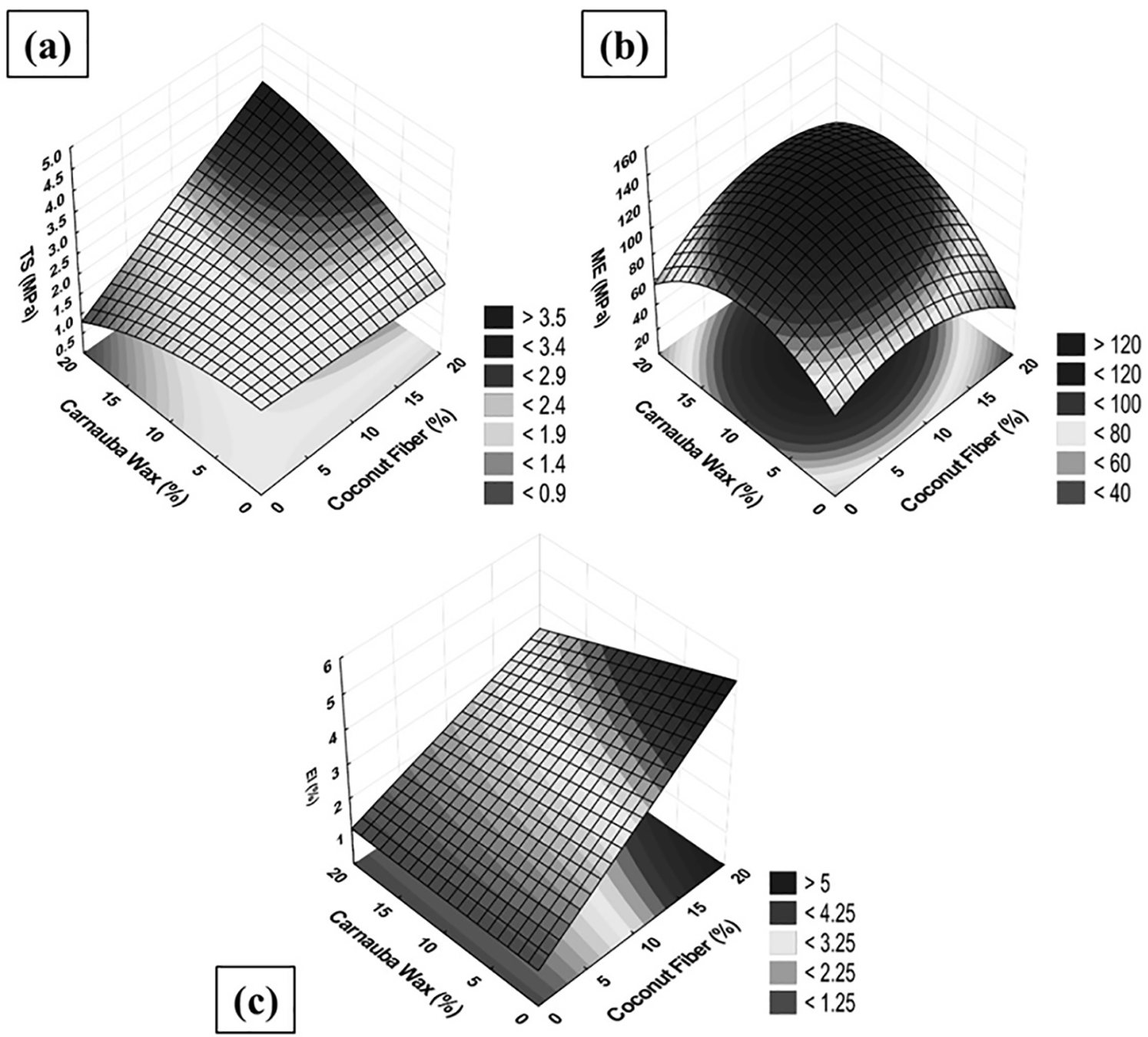

Figure 3. Response surfaces for (a) tensile strength (TS), (b) modulus of elasticity (ME) and (c) elongation at break (El) of biocomposites as a function of coconut fiber and carnauba wax contents.

with low flexibility, as show the micrographs in Figures 1 (a) and 1(e). The coconut fiber has a great elongation at break, corresponding at approximately $30 \%$, according to Ramesh et al. $^{21}$. So, the presence of coconut fibers in the biocomposites grants higher elongation at break to these materials. The negative linear coefficient of the interaction between the coconut fiber and carnauba wax contents indicates an antagonistic effect of these factors on the elongation variation. This observation can be explained by the structural defects caused by an excessive addition of wax and fibers, such as pores and wax agglomeration, as well as the increase in stiffness, which cause a reduction in elongation at break, as observed by Mehyar et al. ${ }^{17}$ and Chiumarelli and Hubinger ${ }^{10,19}$.

\section{Conclusions}

Through optical microscopy it was possible to observe a more compact structure and a better interaction between the corn starch-based matrix and coconut fibers reinforcement in the presence of carnauba wax. The tensile strength and modulus of elasticity rise with the increase in carnauba wax and coconut fiber contents. The elongation at break increases with the addition of coconut fiber, while a decrease occurs with the addition of carnauba wax.

\section{Acknowledgment}

Acknowledgment to UFERSA and CAPES. 


\section{References}

1. Mello LRPF, Mali S. Use of malt bagasse to produce biodegradable baked foams made from cassava starch. Industrial Crops and Products. 2014;55:187-193.

2. Das O, Bhattacharyya D, Sarmah AK. Sustainable eco-composites obtained from waste derived biochar: a consideration in performance properties, production costs, and environmental impact. Journal of Cleaner Production. 2016;129:159-168.

3. Narkchamnan S, Sakdaronnarong C. Thermo-molded biocomposite from cassava starch, natural fibers and lignin associated by laccase-mediator system. Carbohydrate Polymers. 2013;96(1):109-117.

4. Sanyang ML, Sapuan SM, Jawaid M, Ishak MR, Sahari J. Effect of Plasticizer Type and Concentration on Tensile, Thermal and Barrier Properties of Biodegradable Films Based on Sugar Palm (Arenga pinnata) Starch. Polymers. 2015;7(6):1106-1124.

5. Lara SC, Salcedo F. Gelatinization and retrogradation phenomena in starch/montmorillonite nanocomposites plasticized with different glycerol/water ratios. Carbohydrate Polymers. 2016;151:206-212.

6. Belaadi A, Bezazi A, Bourchak M, Scarpa F, Zhu C. Thermochemical and statistical mechanical properties of natural sisal fibres. Composites Part B: Engineering. 2014;67:481-489.

7. Gurunathan T, Mohanty S, Nayak SK. A review of the recent developments in biocomposites based on natural fibres and their application perspectives. Composites Part A: Applied Science and Manufacturing. 2015;77:1-25.

8. Jawaid M, Sapuan SM, Alothman OY, eds. Green Biocomposites: Manufacturing and Properties. Cham: Springer International Publishing; 2017.

9. Ramírez MGL, Satyanarayana KG, Iwakiri S, de Muniz GB, Tanobe B, Flores-Sahagun TS. Study of the properties of biocomposites. Part I. Cassava starch-green coir fibers from Brazil. Carbohydrate Polymers. 2011;86(4):1712-1722.

10. Chiumarelli M, Hubinger MD. Evaluation of edible films and coatings formulated with cassava starch, glycerol, carnauba wax and stearic acid. Food Hydrocolloids. 2014;38:20-27.

11. Rodrigues DC, Caceres CA, Ribeiro HL, Abreu RFA, Cunha $\mathrm{AP}$, Azeredo HMC. Influence of cassava starch and carnauba wax on physical properties of cashew tree gum-based film. Food Hydrocolloids. 2014;38:147-151.
12. ASTM International. ASTM E104-02(2012) - Standard Practice for Maintaining Constant Relative Humidity by Means of Aqueous Solutions. West Conshohocken: ASTM International; 2012.

13. ASTM International. ASTM D3039/D3039M-14 - Standard Test Method for Tensile Properties of Polymer Matrix Composite Materials. West Conshohocken: ASTM International; 2014.

14. Jouki M, Khazaei N, Ghasemlou M, HadiNezhad M. Effect of glycerol concentration on edible film production from cress seed carbohydrate gum. Carbohydrate Polymers. 2013;96(1):39-46.

15. Edhirej A, Sapuan SM, Jawaid M, Zahari NI. Cassava/sugar palm fiber reinforced cassava starch hybrid composites: Physical, thermal and structural properties. International Journal of Biological Macromolecules. 2017;101:75-83.

16. López JP, Mutjé P, Carvalho AJF, Curvelo AAS, Gironès J. Newspaper fiber-reinforced thermoplastic starch biocomposites obtained by melt processing: Evaluation of the mechanical, thermal and water sorption properties. Industrial Crops and Products. 2013;44:300-305.

17. Mehyar GF, Al-Ismail K, Han JH, Chee GW. Characterization of Edible Coatings Consisting of Pea Starch, Whey Protein Isolate, and Carnauba Wax and their Effects on Oil Rancidity and Sensory Properties of Walnuts and Pine Nuts. Journal of Food Science. 2012;77(2):E52-E59.

18. Ibrahim H, Farag M, Megahed H, Mehanny S. Characteristics of starch-based biodegradable composites reinforced with date palm and flax fibers. Carbohydrate Polymers. 2014;101:11-19.

19. Chiumarelli M, Hubinger MD. Stability, solubility, mechanical and barrier properties of cassava starch - Carnauba wax edible coatings to preserve fresh-cut apples. Carbohydrate Polymers. 2012;28(1):59-67.

20. Kaewtatip K, Thongmee J. Studies on the structure and properties of thermoplastic starch/luffa fiber composites. Materials \& Design. 2012;40:314-318.

21. Ramesh M, Palanikumar K, Reddy KH. Plant fibre based bio-composites: Sustainable and renewable green materials. Renewable and Sustainable Energy Reviews. 2017;79:558-584. 